\title{
Titanium-based photocatalysis as the pretreatment for ultrafiltration of secondary municipal effluent with low concentration of organic matters
}

\author{
H. Liu \& L. Song \\ Department of Civil Engineering, Centre for Water Research, \\ National University of Singapore, Singapore
}

\begin{abstract}
Ultrafiltration (UF) has been regarded as a cost-effective option compared to NF and RO for the municipal effluent reclamation process. But the fouling caused by organic matter from the biologically treated sewage effluent is still a serious problem in the process. The photocatalysis was employed as the pretreatment measure for the ultrafiltration of secondary effluents. The fouling potential $\mathrm{k}$ was significantly lowered by this pretreatment measure. The effects of catalyst type (anatase, rutile, and Degussa P-25), catalyst dosage, $\mathrm{pH}$ value, and UV light intensity on fouling potential variation and dissolved organic carbon (DOC) removal were investigated. The results showed that the presence of UV and $\mathrm{TiO}_{2}$ improved DOC removal ratio. The effect of photocatalyst type on fouling potential abatement was compared. The $\mathrm{pH}$ value and catalyst concentration were optimized to get the highest fouling potential reduction and DOC removal efficiency.
\end{abstract}

Keywords: secondary effluents, photocatalysis, titanium dioxide, ultrafiltration, membrane fouling, fouling potential, pre-treatment, wastewater reclamation.

\section{Introduction}

The low pressure-driven membrane processes such as microfiltration and ultrafiltration are increasingly applied in drinking water, industrial water production and wastewater treatment these years. The membrane process has the advantage of compactness, good retention and separation effects for suspended 
and colloidal organic and inorganic substances, pathogenic bacteria, and microorganism, compared with conventional separation processes [1]. However, the fouling caused by the organic and inorganic substances is still a disadvantage for the development of membrane technology. In the area of wastewater reclamation, ultrafiltration (UF) has been regarded as a cost-effective option compared to NF and RO for the municipal effluent reclamation process [2]. But the fouling caused by organic matter from the biologically treated sewage effluent is still a serious problem in the process [3].

Photocatalysis has recently become a common word and various products using photocatalytic functions have been commercialized [4]. Among many candidates for photocatalysis, $\mathrm{TiO}_{2}$ based photocatalysis is more frequently used for industrial application at present and also probably in the future due to its efficient photoactivity, the highest stability, the lowest cost and, more importantly, its safety. Upon the absorption of sufficiently energetic light $(\mathrm{i}<387 \mathrm{~nm})$ by $\mathrm{TiO}_{2}$, an electron is promoted to the higher energy conduction band (CB), leaving a positively charged hole in the valence band (VB). The electron and hole can migrate to the surface of the semiconductor. The electronhole pairs can either recombine or participate in chemical reactions with surface adsorbed species. Oxidation of water (or hydroxide ions) by the valence-band holes $\left(\mathrm{h}_{\mathrm{VB}}^{+}\right)$can produce the hydroxyl radical $(\mathrm{HO} \bullet)$. The conduction-band electrons $\left(\mathrm{e}_{\mathrm{CB}}^{-}\right)$can react with molecular oxygen to form the superoxide radicalanion $\left(\mathrm{O}_{2}{ }^{-}\right)$or hydroperoxyl radicals $\left(\mathrm{HO}_{2}{ }^{\bullet}\right)$. In addition, $\mathrm{h}_{\mathrm{VB}}^{+}$and $\mathrm{e}_{\mathrm{CB}}^{-}$can react directly with adsorbed pollutants. The radicals thus formed, dioxygen and water can participate in further reactions, resulting ultimately in mineralization of the organic pollutants. Many organic contaminants can be almost completely mineralized by $\mathrm{UV} / \mathrm{TiO}_{2}$. The bio-degradation of these pollutants is often very slow and conventional treatments are mostly ineffective and not environmentally compatible, while photocatalysis offers faster, controllable and environmentally benign process with respect to conventional treatment technologies [4].

The objective of this study is to investigate the possibility of photocatalysis as the pretreatment for hollow fiber ultrafiltration membrane organic fouling reduction in the process of reclamation of biologically treated secondary effluent. Accordingly the factors influence the fouling reduction effect will be addressed. Our hypothesis that the photocatalysis can influence the membrane fouling formation negatively or positively is based on the two understanding of the process. First, the photocatalysis treatment can lower the organic load to membrane surface due to the mineralization effect (converted to $\mathrm{CO}_{2}$ and $\mathrm{N}_{2}$ ). On the other hand, photocatalysis process can effectively degrade the long chain organic components or macromolecules of to smaller ones, which can decrease the aromaticity of the feed water and accordingly the adsorption effect of degraded organic matters to the membrane surface will be decreased, which will retard the formation of fouling. Relatively, few studies using photocatalysis as pretreatment have been conducted for the enhancement of permeation flux and abatement of fouling in the ultrafiltration membrane process.

As a method for membrane fouling reduction, the biologically treated secondary effluent was firstly pretreated by photocatalytical reaction before the 
ultrafiltration process. The parameters, such as photocatalyst type, UV irradiation, reaction time, $\mathrm{pH}$ values, etc were changed to investigate their effects on the fouling potential of the fabricated hollow fiber ultrafiltration membrane.

\section{Materials and methods}

\subsection{Hollow fiber ultrafiltration set-up}

In this study, the cross-flow hollow fiber ultrafiltration membrane (Nitto Denko Corp.) was used to study the effect of photocatalystical pretreatment on the membrane performance. The schematic diagram of cross-flow ultrafiltration experimental set-up is shown in Figure 1. The outside-in cross-flow membrane module was fabricated with two (OD3/8 inches) SS316 Tees and transparent Swagelok Perfluoroalkoxy(PFA) or Quartz tube (OD 3/8 inches). The hollow fiber membrane lumens were sealed with epoxy resin (chemically stable tested under the experimental environment) into the two ends of the stainless steel tees.

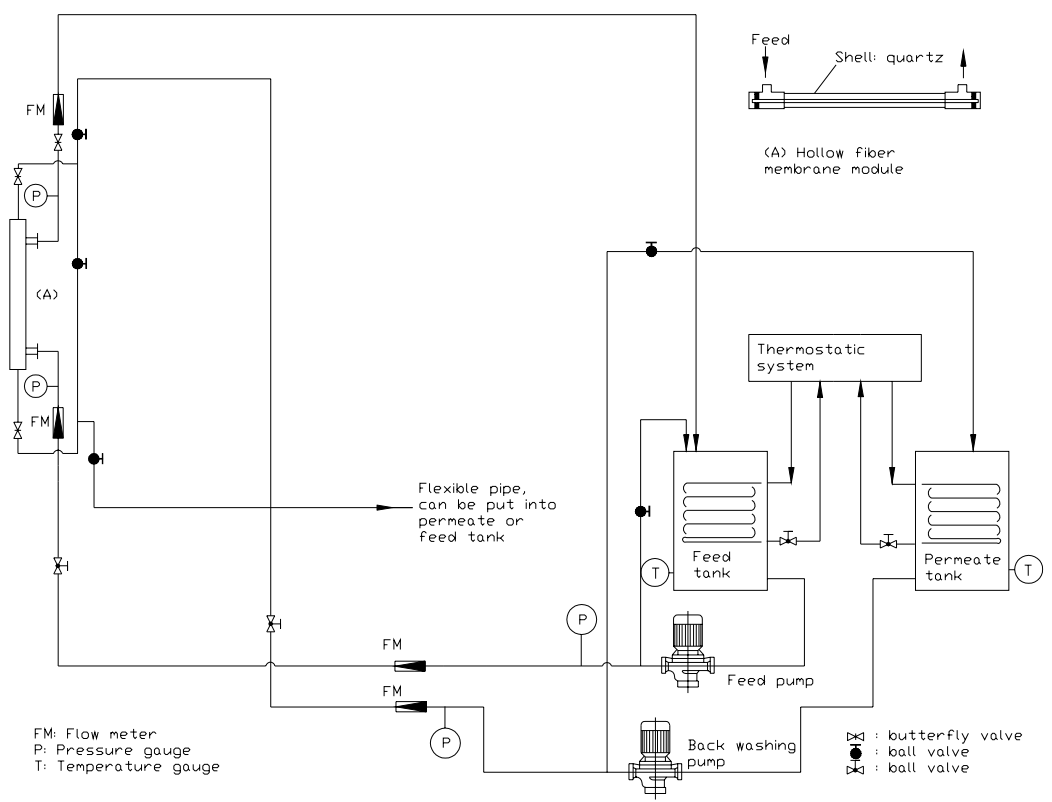

Figure 1: $\quad$ Schematic diagram of the experimental set-up.

The schematic diagram of cross-flow hollow fiber ultrafiltration membrane module is shown in Figure 2.

The wastewater with and without pretreatment was pumped into the hollow fiber membrane module (the effective hollow fiber length $20 \mathrm{~cm}$, effective membrane surface area $0.0035 \mathrm{~m}^{2}$ ). The operating pressure and cross-flow velocity were controlled at $123 \mathrm{kPa}$ and $0.5 \mathrm{~m} / \mathrm{s}$ by means of by-pass and regulating valves. Reynolds number and shear stress at the wall were 1682 and 
1.33 $\mathrm{Pa}$, respectively. The permeate flux was recycled into feed tank. The membrane used in this study was external pressure type hollow fiber UF membrane NTU-3306 (Nitto Denko Corp., Japan) with an average pore size of 6,000 MWCO. Capillary I.D./O.D 1.3/1.9 mm Material: Polysulfone The hollow fiber module was back washed with deionized water and then cleaned with $0.01 \mathrm{~N} \mathrm{NaOH}$ and $0.01 \mathrm{~N} \mathrm{HCl}$ solution and deionized water after each test. The permeate flux can be recovered to $95-98 \%$ of that of the virginal membrane. After 10 times' test with one hollow fiber membrane module, a new membrane module will be employed.

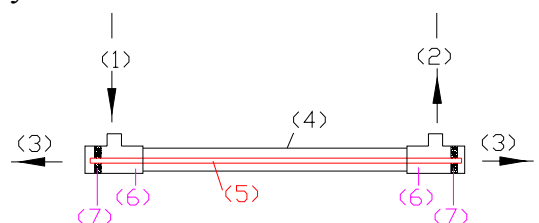

Figure 2: Hollow fiber ultrafiltration membrane module (1) feed water (2) retentate (3) permeate (4) module shell (material, PFA or quartz) (5) hollow fiber membrane (6) stainless steel tee, $3 / 8$ inches (7) epoxy.

\subsection{Apparatus}

\subsubsection{Total organic carbon}

TOC was measured by 1010 Total Organic Carbon Analyzer (O. I. Analytical, College Station, TX, USA). All samples were filtered through $0.45 \mu \mathrm{m}$ membrane (Pall corp.) prior to the TOC measurement. Thus, the TOC values obtained are, in fact, dissolved organic carbon (DOC) values.

\subsubsection{Molecular weight (MW) distribution}

The wastewater effluent after each pretreatment was subjected to molecular weight distribution measurement. High performance size exclusion chromatography (HPSEC, Shimadzu Class VP series Shimadzu Corp., Japan) was used to determine the MW distribution of wastewater. Standards of MW of various polystyrene sulfonates (PSS: 4,300, 6,800, and 13,000 Da) and Acetone $(58 \mathrm{Da})$ were used to calibrate the equipment. Two columns (Waters Ultrahydrogel 250 and 120) connected in series were used to cover a molecular weight range of 200-80,000 Da. The column temperature was maintained at room temperature and the mobile phase (phosphate buffer $0.0026 \mathrm{M}$ $\mathrm{KH}_{2} \mathrm{PO}_{4}+0.0023 \mathrm{M} \mathrm{K}_{2} \mathrm{HPO}_{4}+0.090 \mathrm{M} \mathrm{NaCl}, \mathrm{pH} 6.8$, producing an ionic strength of $0.1 \mathrm{M}$ ) flow rate was maintained at $0.7 \mathrm{~mL} / \mathrm{min}$.

\subsection{Irradiation experiments}

\subsubsection{Reagents}

The photocatalyst powder used in this work was commercial titanium dioxide $\mathrm{TiO}_{2}$, Degussa P25 (about 70\% anatase, with a BET surface area of 
approximately $50 \mathrm{~m}^{2} / \mathrm{g}^{-1}$, Degussa AG, Germany), $\mathrm{TiO}_{2}$ anatase nanopowder (99.7\%, spec. surface $200-220 \mathrm{~m}^{2} / \mathrm{g}$, Aldrich Corp.) and $\mathrm{TiO}_{2}$ rutile nanopowder (99.5\%, spec. surface $130-190 \mathrm{~m}^{2} / \mathrm{g}$, Aldrich Corp.). $\mathrm{TiO}_{2}$ suspensions in wastewater at concentrations of 50,100 and $500 \mathrm{mg} / 1$ were prepared for the photocatalystic reaction.

\subsubsection{Photocatalytic activity}

Photocatalytic degradation tests were carried out in a thermostatic $\left(33^{\circ} \mathrm{C}\right)$, and magnetically agitated reactor. The UV lamp was put directly $10-12 \mathrm{~cm}$ above the solution surface in the reactor. Three UV lamps were employed in the experiment, 365nm low pressure mercury lamp, (FL 15BLB 15W $\times 2$, Sanyo Denki, Japan), germicidal $254 \mathrm{~nm}$ low pressure mercury lamp (Sunlite G20T10, $20 \mathrm{~W} \times 2$, USA), customer-made medium high pressure mercury lamp $400 \mathrm{~W}$ (XHDSHP-400, China) emitting visible and near-UV light. The lamps were turned on for at least $30 \mathrm{~min}$ prior to irradiation of wastewater solution samples to ensure uniform lamp output. The UV intensity was measured with a digital spectrophotometer (Model E2, B. Hagner AB, Solna, Sweden). At regular intervals of time, water sample of $30 \mathrm{ml}$ were collected, filtered through a disc filter (pore size $0.45 \mathrm{~mm}$, Pall Corp.) and analyzed with TOC and HPSEC.

\section{Results and discussion}

\subsection{Wastewater photooxidation kinetics}

In the presence of $\mathrm{TiO}_{2}$ and UV light, the organic matter was degraded gradually. At the low TOC level, less than $10 \mathrm{mg} / \mathrm{l}, \mathrm{TiO}_{2}$-photocatlyzed wastewater oxidation process generally exhibits pseudo first-order kinetics with respect to the dissolved TOC (Figure3); comparable kinetics were observed at relatively high TOC level, $18.9 \mathrm{mg} / \mathrm{l}$ (data not shown). This behaviour is consistent with previous observations by Chen et al [5].

The apparent first-order constant $K$ of the degradation process (generally in $\mathrm{min}^{-1}$ ) will be obtained from kinetic analysis. The initial concentration of the reactant $\left(\mathrm{c}_{0}\right)$, the apparent first-order constant $K$ (generally in $\min ^{-1}$ ) could be obtained from experimental data plotted according to:

$$
\ln \left(\frac{c_{0}}{c}\right)=K t,
$$

with $\mathrm{c}$ is the concentration (in $\mathrm{mg} / \mathrm{l}$ ) of the reactant at the illumination time (t) in min. Once plotted according to above equation, data presented a linear correlation with $\mathrm{R}^{2}>90$. The TOC degradation rate $K$ is deeply affected by the catalyst concentration, and $0.5 \mathrm{~g} / 1 \mathrm{P} 25 \mathrm{TiO}_{2}$ is the optimal concentration for TOC degradation, compared with other concentrations under the experiment condition. In addition, the degradation efficiency of three catalysts, P25, anatase, rutile under the $365 \mathrm{~nm}$ medium high pressure UV lamp was also compared (Figure 4). At the same concentration, $0.5 \mathrm{~g} / \mathrm{l}$, nanopowder anatase exhibits the highest TOC removal efficiency, while that of the rutile phase $\mathrm{TiO}_{2}$ 
nanopowder is the lowest. The efficiency of P25 is just between them, and this also coincides with catalyst's composition, about $70 \%$ is anatase phase $\mathrm{TiO}_{2}$. The experiment shows that the anatase phase $\mathrm{TiO}_{2}$ is the major component which is responsible for the effective TOC degradation. This coincides with some other researcher's works. Antase $\mathrm{TiO}_{2}$ is the most catalytically active form for the photodegradation of aqueous organic pollutants [6].

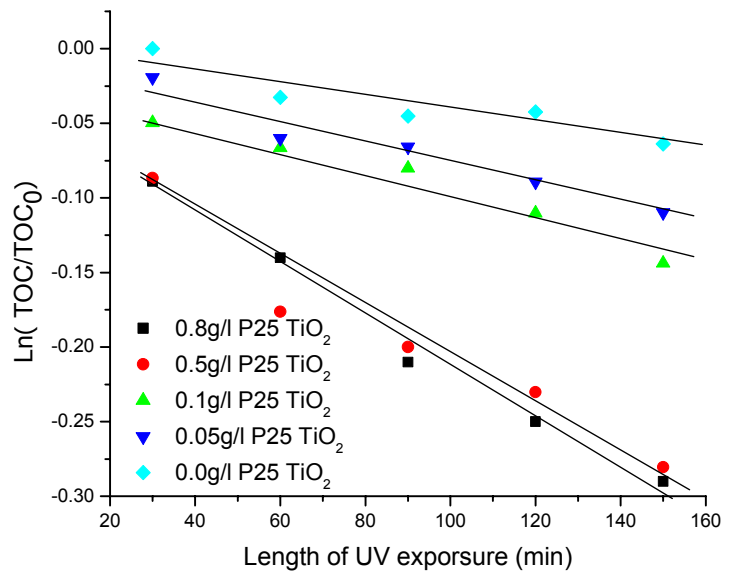

Figure 3: Photocatalysis reaction simulation with the pseudo first-order kinetics.

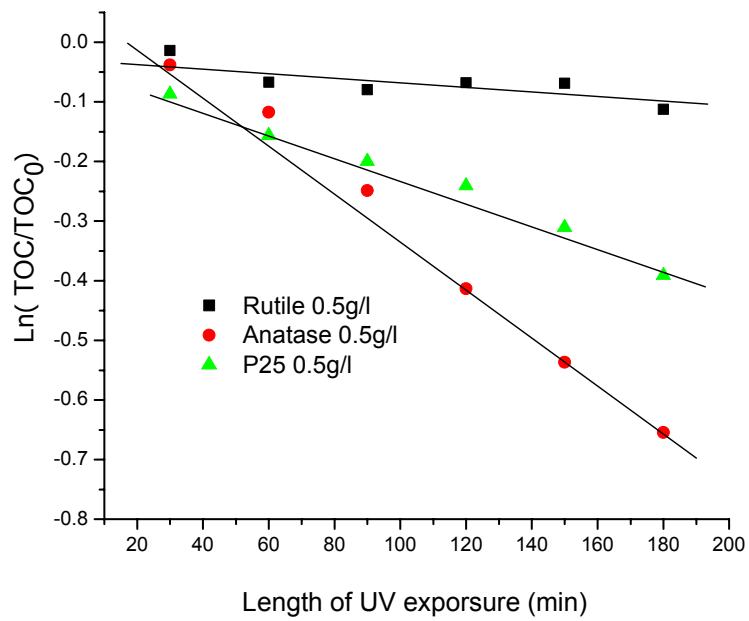

Figure 4: The effect of catalyst type on TOC degradation rate. 


\subsection{Fouling potential of treated water on ultrafiltration membrane}

The photocatalytically treated wastewater was further put into the hollow fiber module to test the fouling potential. Fouling potential is crucial parameter to exam the fouling tendency of the feed water. The fouling potential of feed water is defined as the increment of membrane resistance per unit volume of permeates collected for a unit area of membrane surface [7].

$$
k=\frac{R_{t}-R_{0}}{V_{t}}
$$

where $k$ is the fouling potential, $R_{t}$ is the resistance of the membrane at a given time $t, R_{0}$ is the clean membrane resistance, $V_{t}$ is the total volume of permeate per unit membrane area generated at a given time $t$ from the beginning of the filtration process. The detailed deduction and calculation methods can refer to the works of Song et al [7].

Table 1: The fouling potential of the photocatalytically treated secondary effluent.

\begin{tabular}{|c|c|c|c|c|}
\hline $\begin{array}{c}\mathrm{TiO}_{2} \text { type } \\
\text { and concentration } \\
(\mathrm{mg} / \mathrm{l})\end{array}$ & UV type & $\mathrm{pH}$ & $\begin{array}{c}\text { Reaction } \\
\text { time(min) }\end{array}$ & $\begin{array}{c}\text { Fouling } \\
\text { potential }(\mathrm{Pa} \\
\left.\mathrm{s} / \mathrm{m}^{2}\right)\end{array}$ \\
\hline 0 & N. A. & 7.81 & 0 & $2.130 \mathrm{E}+10$ \\
\hline $\mathrm{P} 25,500$ & UV365 MHP & 7.63 & 120 & $6.824 \mathrm{E}+09$ \\
\hline P25, 500 & UV365 MHP & 7.56 & 150 & $3.039 \mathrm{E}+09$ \\
\hline P25, 500 & UV365 LP & 7.8 & 150 & $9.859 \mathrm{E}+09$ \\
\hline P25, 500 & UV254 LP & 7.6 & 120 & $8.846 \mathrm{E}+09$ \\
\hline Anatase,500 & UV365 MHP & 7.8 & 150 & $1.426 \mathrm{E}+9$ \\
\hline Rutile, 500 & UV365 MHP & 7.6 & 150 & $1.532 \mathrm{E}+10$ \\
\hline P25, 500 & UV254 LP & 4.35 & 120 & $4.045 \mathrm{E}+09$ \\
\hline P25, 500 & UV254 LP & 3.31 & 120 & $6.585 \mathrm{E}+09$ \\
\hline
\end{tabular}

MHP: medium high pressure lamp, LP: low pressure lamp.

The fouling potential tests showed that the photocatalysis pretreatment greatly lowered the fouling potential of the feed water, and reduced even to about one magnitude in some cases. For instance, the fouling potential of the photocatalytically degradated wastewater reduced about $90 \%$ at the condition of $0.5 \mathrm{~g} / 1$ anatase $\mathrm{TiO}_{2}, 150 \mathrm{~min}$ reaction time. The UV intensity, catalyst type, the $\mathrm{pH}$ value and UV exposure time will greatly influence the fouling potential of the photooxidized wastewater (Table 1). Generally speaking, the longer the reaction time, the greater the fouling potential reduced. At the same $\mathrm{pH}$ level, reaction time and with the same catalyst, the wastewater under medium high pressure UV lamp irradiation demonstrated the highest fouling porential reduction. This is due to the higher UV intensity of medium high pressure 
mercury lamp $\left(23.1 \mathrm{~mW} / \mathrm{cm}^{2}\right)$ than the other two low pressure lamps, germicidal $254 \mathrm{~nm}$ and black light blue $365 \mathrm{~nm}$ (intensity, $2.3 \mathrm{~mW} / \mathrm{cm}^{2}$ and $0.5 \mathrm{~mW} / \mathrm{cm}^{2}$ respectively). In addition, the lower $\mathrm{pH}$ value showed higher fouling potential reduction than high $\mathrm{pH}$ value, and this is also coincident with the observation of photooxidation kinetics. As one of the major components responsible for the oxidization for the organic matters, the concentration of hydroxyl radical [HO•] is critical for the degradation rate of the reaction. According to the reaction equations, the concentration of [HO-] increases with the concentration of $\left[\mathrm{H}^{+}\right]$in the water. At low $\mathrm{pH}$ value, about 3-4, and hydrogen concentration is high. Accordingly, the photodegradation rate is greater than that at relatively high $\mathrm{pH}$ 7.8 , so the lower $\mathrm{pH}$ value showed higher fouling potential reduction.

\subsection{The change in the properties of the photooxidized wastewater}

The photooxidation process will inevitably lead to the changes in the physical and chemical properties, such as the molecular weight and aromaticity of the organic matters [9]. The HPLC-SEC test gave us qualitative information about the changes in molecular weight distribution by the reaction. Long chain organic compounds were degraded to relatively small molecules. And some organic substrates were converted to carbon dioxide, nitrogen and water. The average molecular weight of reactants declines as the function of reaction time.

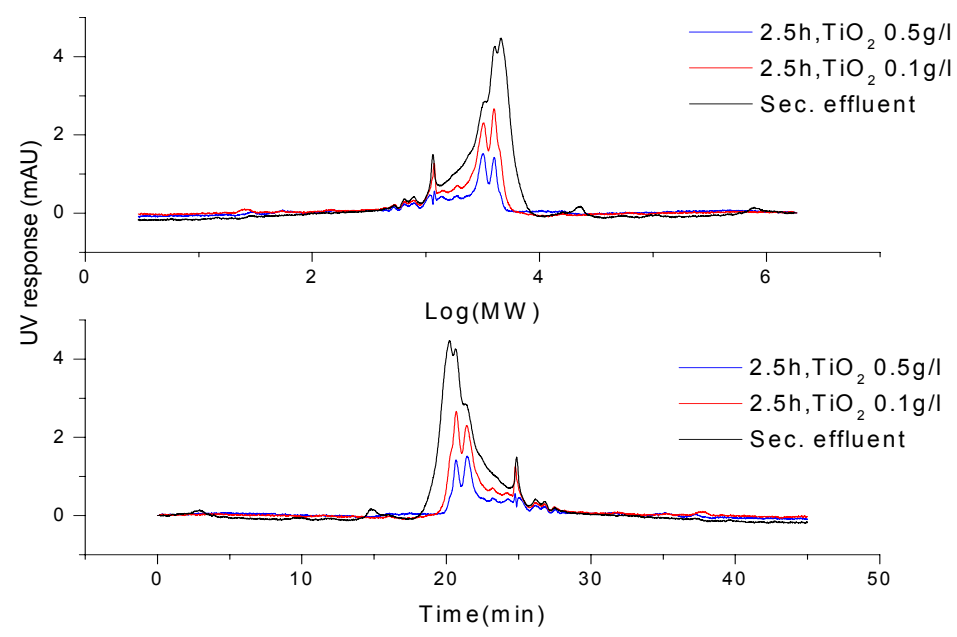

Figure 5: $\quad \mathrm{MW}$ distributions of secondary effluent and $\mathrm{UV} / \mathrm{TiO}_{2}$ treated secondary effluent measured by the HPLC-SEC with UV detection.

Generally speaking, long chain molecules or macromolecules have more negative effect for the fouling control than micromolecules [8]. The change in the molecular size contributes to the decrease of fouling potential to some extent. Compared with the photooxidized effluent, the raw effluent has relatively larger 
molecular size, as shown in Figure 5. There are some bigger molecules in the raw effluent, about $20 \mathrm{k}$ Da, corresponding to the peak at about $15 \mathrm{~min}$, while that peak is completely disappeared in the treated effluent. It means that the bigger molecules were cleaved into smaller ones (the sharp peak at about $22 \mathrm{~min}$ ), or mineralized. In addition, the smaller molecules in the raw water, as the sharp peak shown at $25 \mathrm{~min}$, also disappeared, which is the evidence of the mineralization of small organic molecules. The test also showed that the treated effluent narrows the molecular weight distribution (from about $1 \mathrm{k}$ Da to $6 \mathrm{k} \mathrm{Da}$, at $0.5 \mathrm{~g} / 1 \mathrm{P} 25 \mathrm{TiO}_{2}, 150 \mathrm{~min}$ reaction) compared with the raw effluent (from about $300 \mathrm{Da}$ to $20 \mathrm{k} \mathrm{Da})$. The ratio of weight-average molecular weight $(\mathrm{Mw})$ to number-average molecular weight $(\mathrm{Mn}), \mathrm{Mw} / \mathrm{Mn}$, changes from 2.35 to 1.21, which implies that the dissolved organic components in the treated secondary effluent become simpler. Another distinctive feature is that the amplitudes of the peaks of treated water are greatly reduced, which means that the concentration of the organic matters are abated after the treatment. Additionally, the concentration of the catalyst will affect the oxidation process. Lower catalyst concentration will produce relatively wider molecular weight distribution with the same UV exposure length (Figure 5). Almost all the phenomena in fouling potential test are reflected on the photooxidation kinetics. The oxidation progress is closely connected with the molecular properties, such as the morphology and aromaticity of organic components, and correspondingly affects the fouling potential of the oxidized wastewater.

\section{Conclusion}

Titanium dioxide based photocatalysis is an effective measure for the fouling abatement on hollow fiber ultrafiltration membrane. The fouling potential $\mathrm{k}$ can be greatly lowered to as much as $90 \%$ by this pretreatment measure. On the one hand, photocatlysis can effectively reduce the organic load to membrane surface by the mineralization process, and on the other hand its alteration to the properties of organic matters, such as molecular weight distribution, aromaticity also favorably reduces the potential of fouling formation. The anatase phase $\mathrm{TiO}_{2}$ is more efficient for the fouling reduction than $\mathrm{P} 25$ and rutile $\mathrm{TiO}_{2}$. The reduction in fouling potential is higher at low $\mathrm{pH}$ value about 4.35 and under higher UV intensity, which coincides with the photooxidation kinetics. Titanium dioxide based photocatalysis is a novel process for the fouling reduction of ultrafiltration membrane, and more research efforts are needed to further test and optimize the process.

\section{References}

[1] K. Azrague, P. Aimar, 2006. Applied Catalysis B: Environmental 72 (2006) 197-205

[2] H.K. Shon, S. Vigneswarana. 2004. Water Research 38 1933-1939

[3] Nidal Hilal, Oluwaseun O. Ogunbiyi. 2005. Separation Science and Technology, 40: 1957-2005, 
[4] Hoffmann, M., et al. 1995. Chem. Rev. 95, 69-96

[5] Chen, P.H., Jenq, C.H., 1998. Environ. Intern. 24 (8), 871-879.

[6] Nádia R.C. Fernandes Machado. 2005. Catalysis Today 107-108, 595-601

[7] L. Song, K.L. Chen. Colloid Interface Sci. 271 (2004) 426.

[8] I.C. Escobar, E.M. Hoek; C.J. Gabelich; F.A. DiGiano; et al (2005) Amer. Wat. Works Ass. J 97,8

[9] Namguk Her, Gary Amy (2003) Water Research 37, 4295-4303 